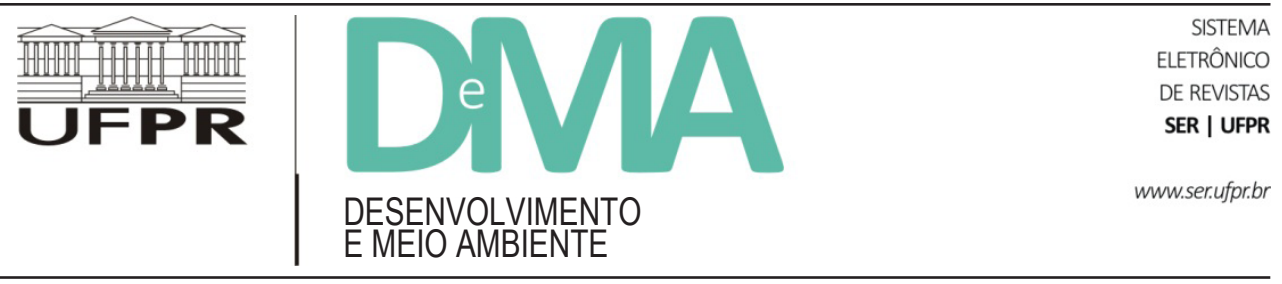

\title{
O desafio da comunicação da pesquisa sobre riscos climáticos na agricultura familiar: a experiência de uso de cartilha educativa no Semiárido nordestino
}

\section{The Challenge of Communicating Research on Climate Change Related Risks to Family Farmers: The Experience of Using a Didactic Booklet in the Brazilian Semiarid Northeast}

\author{
Gabriela LITRE $^{1 *}$, Melissa CURI ${ }^{1}$, Patrícia S. MESQUITA ${ }^{1}$, Stephanie NASUTI ${ }^{1}$, Gledson ROCHA ${ }^{2}$ \\ ${ }^{1}$ Centro de Desenvolvimento Sustentável, Universidade de Brasília (UnB), Brasília, DF, Brasil. \\ ${ }^{2}$ Faculdade São Francisco de Barreiras (FASB), Barreiras, BA, Brasil. \\ *E-mail de contato: gabrielalitre@yahoo.com
}

Artigo recebido em 30 de outubro de 2016, versão final aceita em 16 de fevereiro de 2017.

RESUMO: Com foco nos agricultores familiares do Semiárido nordestino - um dos segmentos da população brasileira mais vulnerável às mudanças e às variabilidades climáticas - este artigo apresenta o processo de elaboração e de divulgação de uma cartilha educativa, criada de maneira colaborativa, para compartilhar as percepções desses agricultores sobre os riscos climáticos. A cartilha também visou divulgar opções de estratégias adaptativas desenvolvidas pelos próprios atores locais. Uma equipe de pesquisa interdisciplinar, integrante da sub-rede Mudanças Climáticas e Desenvolvimento Regional (MCDR/Rede CLIMA), conduziu 1.140 entrevistas semiestruturadas em quatro áreas do Semiárido brasileiro: Seridó Potiguar-RN, Gilbués-PI, Juazeiro-BA e Chapada do Araripe-CE. Os questionários aplicados levantaram, entre outros, dados sobre as percepções dos agricultores familiares a respeito das mudanças do clima, seus valores culturais e suas expectativas a respeito do futuro dos seus modos de vida rurais. A partir dessas informações, criou-se uma cartilha educativa para restituir os dados coletados. Privilegiando o diálogo e a troca de saberes ou, nas palavras de Habermas, "a negociação da definição de situação", o instrumento de comunicação escolhido partiu do pressuposto de que as comunidades tendem a confiar em novas informações quando estas possuem, na sua percepção, relevância, credibilidade e legitimidade. Os resultados gerais da experiência demonstraram que possíveis barreiras sociais e culturais (tais como a incompreensão inicial entre cientistas e usuários do conhecimento) podem ser superadas por meio de ações colaborativas entre a academia, os tomadores de decisão e os usuários finais. A elaboração da cartilha encorajou o trabalho horizontal para identificar riscos climáticos e possíveis medidas de adaptação.

Palavras-chave: mudanças climáticas; restituição de resultados de pesquisa; semiárido; agricultura familiar; comunicação científica. 
ABSTRACT: With a focus on the perceptions of smallholder / family farmers from the North-eastern Semiarid region of Brazil - one of the most climate change-vulnerable populations of the country-, this article describes the collaborative creation and dissemination process of a didactic booklet (cartilha educativa, in Portuguese) aimed at sharing visions of climate change-related risks and adaptation strategies of smallholder farmers from the region. The research team, member of the subnet on Climate Change and Regional Development (MCDR/Rede CLIMA), applied 1.140 semi-structured questionnaires in four selected areas: Seridó Potiguar-RN, Gilbués-PI, JuazeiroBA and Chapada do Araripe-CE. The survey focused on, among others, family farmers' perceptions on climatic risks and adaptation options, as well as their cultural values and expectations regarding the future of their rural livelihoods. Based on those perceptions and expectations, a didactic booklet was chosen as the best instrument to co-create knowledge about climatic change impact and adaptation strategies in the region. By prioritizing dialogue and the exchange of viewpoints - or, in Habermas' words, "the negotiation of common definitions of situations"-, the team assumed that potential users are more likely to trust knowledge, and may therefore be willing to act on it, when from their perspective it meets three criteria: relevance, credibility, and legitimacy. In general terms, the experience of using this didactic booklet confirmed that barriers to successful climate change adaptation (such as mutual incomprehension between scientists and end-users) could be overcome by creating collaborative enterprises. The co-creation of the didactic booklet, which included switching roles between knowledge producers and end-users, facilitated horizontal work towards the identification of climaterelated risks and possible adaptation measures.

Keywords: climatic change; scientific communication and feedback; semiarid Brazil; family farming.

\section{Introdução}

Em termos gerais, risco pode ser definido como a possibilidade de um dano potencial ou de que algo ruim aconteça. $\mathrm{O}$ conceito adquiriu relevância na teoria social a partir das contribuições de Giddens et al. (1997) e Beck (1998). Para esses teóricos, os riscos ambientais e tecnológicos de graves consequências são conceitos-chave para compreendermos os processos sociais em curso na sociedade contemporânea.

Ainda que Beck não se detenha em definições detalhadas do que entende por risco, com esse conceito, ele abrange os riscos ecológicos, químicos, nucleares e genéticos, produzidos industrialmente, externalizados economicamente, individualizados juridicamente, legitimados cientificamente e minimizados politicamente (Beck, 1998).

Os riscos podem trazer consequências incontroláveis, sem limites espaciais, temporais ou sociais, apresentando, assim, sérios desafios às instituições dedicadas a seu controle. Em síntese, trata-se de riscos com efeitos globais, invisíveis e, às vezes, irreversíveis, que Giddens (2000) classifica como externos (advindos da tradição ou da natureza) e fabricados (derivados da ação humana).

No caso dos riscos originados pelas mudanças climáticas, trata-se, na ótica da definição de Giddens, de riscos em grande medida fabricados (derivados da ação humana) e ao mesmo tempo, externos (pois estão intimamente atrelados a natureza). Nesse sentido, a agricultura, especialmente a familiar, é uma das atividades que deve impactar (por meio da emissão de gases de efeito estufa gerada pelo desmatamento e queimadas, entre outros), e ao mesmo tempo ser impactada (por meio dos eventos climáticos extremos como secas e inundações), a incidência de riscos climáticos, pois vincula intimamente a ação humana com a natureza. Os riscos climáticos afetam a agricultura, resultando em grandes modificações na produtividade das culturas, na eficiência dos métodos de produção e, ainda mais importante, nos modos de vida dos agricultores (Vermeulen et al., 2010; Litre \& Bursztyn, 
2015). Riscos derivados da variabilidade climática, como alterações na oferta e distribuição hídrica, na qualidade do solo e disponibilidade de nutrientes, além de mudanças na temperatura, exercerão grande influência sobre o potencial produtivo de muitas das culturas no setor agropecuário (Beddington et al., 2012).

Levando-se em consideração a ligação intrínseca entre a dependência direta de pluviosidade e a agricultura de subsistência, as mudanças climáticas podem resultar em impactos negativos para a parcela mais pobre da população nas áreas mais áridas. Nessas regiões, o estresse hídrico, que sempre foi um fator sazonal presente, tende a se agravar e a afetar a agricultura de subsistência, que é uma importante base da economia local (Obermaier et al., 2009).

No Brasil, o semiárido ocupa cerca de 980 mil km², com uma população de aproximadamente 22,6 milhões de habitantes, o que representa $12 \%$ da população brasileira (IBGE, 2010). Segundo dados do Instituto Nacional do Semiárido - INSA (2014), a população rural dessa região é de 8,6 mi1hões de pessoas, ou seja, 38\% da população rural brasileira reside no semiárido. Ainda conforme o INSA (2014), a maior parte dos agricultores familiares da região semiárida não possui irrigação em suas pequenas propriedades, o que leva o instituto a colocá-los, diante dos riscos climáticos esperados, entre as populações mais vulneráveis frente às mudanças do clima. Nesse contexto, levanta-se a necessidade de uma ampliação do entendimento de como as mudanças climáticas impactam tais habitantes, como eles percebem e se adaptam a tais mudanças e como a comunicação científica no ramo da climatologia pode ser empregada para informar sobre modos de adaptação.

Beck (1998; 1999) e Giddens (2000), ressaltando a necessidade de se elaborar novos conceitos teóricos para entender as vulnerabilidades das sociedades contemporâneas, projetam a análise dos riscos como eixo central de suas abordagens. Esses novos conceitos teóricos incluem formas inovadoras de comunicação do risco, que procuram superar a frequente contradição entre o que cientificamente está sendo comunicado e o que está sendo percebido pelos atores-alvo.

Nesse sentido, a presente pesquisa revelou um paradoxo entre percepções e reações dos atores envolvidos. Por um lado, os agricultores familiares são um dos raros grupos que observam direta e detalhadamente a evolução das principais variáveis climáticas (intensidade e ritmo das precipitações, orientação dos ventos, distribuição temporal dos dias quentes, etc.) e ambientais (fenologia das árvores, comportamentos dos animais, movimento dos astros, etc.). Suas atividades produtivas e sua sobrevivência estão estreitamente ligadas à forma como os fenômenos climáticos ocorrem. Para esse segmento da população brasileira, as manifestações locais das mudanças climáticas estão totalmente evidentes, observadas a partir da experiência do dia a dia.

Por outro lado, estudos no Semiárido brasileiro têm demonstrado que agricultores familiares, em geral, não conseguem interpretar os fenômenos observados, nem os relacionar com o fenômeno da "mudança climática", tão presente na mídia. De fato, os discursos sobre as mudanças climáticas divulgados pelos veículos de comunicação tratam, geralmente, do fenômeno na sua escala global, retratando eventos ou tendências climáticas distantes da realidade do agricultor familiar nordestino: derretimento de geleiras, elevação do nível do mar, alagamento de ilhas remotas, aquecimento global, etc. Assim, o termo, apesar de ter se tornado comum, nem sempre consegue ser identificado pela população como parte da sua realidade, pelo fato de 
que o discurso midiático não está adaptado à escala geográfica e temporal na qual os fenômenos estão sendo observados.

Assim, existe um hiato entre as informações divulgadas pela mídia e as informações que seriam úteis para realmente instruir certos grupos de população, que vivenciam diretamente os fenômenos climáticos, mas não os entendem. A escassez de material educacional de qualidade e adaptado aos distintos públicos-alvo a respeito das mudanças climáticas também impõe os desafios de se encontrar uma linguagem que atinja diversos grupos de atores e de se criar um discurso acessível e prático. Essa observação frequentemente se estende aos profissionais atuantes na extensão rural e na assistência técnica, que, apesar dos seus esforços, geralmente ainda não foram devidamente treinados para lidar com a recorrente manifestação de variações atípicas do clima.

Esse evidente paradoxo entre percepção do risco climático e não reação face ao risco percebido pode ser entendido a partir das ferramentas conceituais da teoria da ação comunicativa, formulada por Habermas (1984; 1987). Para Habermas, as relações intersubjetivas entre sujeitos e o mundo subjetivo dos atores comunicativos devem ser especialmente levadas em conta quando se busca o entendimento sobre algo:

[...] não é a relação de um sujeito solitário com algo no mundo objetivo que pode ser representado e manipulado mas a relação intersubjetiva entre sujeitos que falam e atuam, assumem quando buscam o entendimento entre si sobre algo. Ao fazer isto, os atores comunicativos movem-se por meio de uma linguagem natural, valendo-se de interpretações culturalmente transmitidas e referem-se a algo simultaneamente em um mundo objetivo, em seu mundo social comum e em seu próprio mundo subjetivo (Habermas, 1984, p. 392).
A mudança de paradigma proposta por Habermas é fruto do abandono de uma compreensão egocêntrica do mundo, cuja fundamentação o autor retira do conceito de descentração de Piaget (Pinto, 1995). Habermas buscará, então, construir um conceito de racionalidade que encontra seus fundamentos nos processos de comunicação intersubjetiva, com vistas a alcançar o entendimento. Essa razão distingue-se completamente da razão instrumental, tão cara ao empirismo das ciências que estudam o clima, que se estrutura no uso não comunicativo do saber em ações dirigidas a um conhecimento confiável, vinculado a uma racionalidade. Por meio do empirismo, a racionalidade instrumental marcou profundamente a autocompreensão da era moderna (Pinto, 1995).

O conceito de razão comunicativa de Habermas pressupõe uma diferenciação entre os mundos objetivo, social e subjetivo. Essa diferenciação, segundo ele, é que distingue o pensamento moderno do modo de pensar mítico. Ao contrário do último, o primeiro assume que as interpretações variam de acordo com a realidade social e natural e que as crenças e valores variam em relação ao mundo objetivo e social.

Outra consequência desse conceito é que ele pressupõe o abandono da relação cognitiva sujeito-objeto por um procedimento cognitivo de natureza intersubjetiva, numa relação sujeito-outro-sujeito, e que só é possível com a progressiva descentração de nossa visão egocêntrica de mundo (Habermas, 1987; Pinto, 1995).

Portanto, com a superação da visão mítica com seu caráter unificador e com o abandono da relação sujeito solitário dominante e consciente frente a um objeto dominado e cognoscível, surge a necessidade, nas palavras de Habermas, de "negociar" a definição da situação analisada. Por meio dessa negociação, os atores em comunicação chegam ao entendimento quanto a pretensões de validade 
criticável. Desse modo, fica, também, demarcada a diferença entre ação comunicativa e ação orientada para o sucesso. Como diz Habermas, a ação comunicativa ocorre

[...] sempre que as ações dos agentes envolvidos são coordenadas, não através de cálculos egocêntricos de sucesso mas através de atos de alcançar o entendimento. Na ação comunicativa, os participantes não estão orientados primeiramente para o seu próprio sucesso individual, eles buscam seus objetivos individuais, respeitando a condição de que podem harmonizar seus planos de ação sobre as bases de uma definição comum de situação. Assim, a negociação da definição de situação é um elemento essencial do complemento interpretativo requerido pela ação comunicativa (Habermas, 1984, p. 285-286).

Foi com esse intuito, proposto por Habermas (1984), de harmonizar os planos de ação individuais sobre as bases de uma definição comum de situação que a presente pesquisa foi desenvolvida na região semiárida nordestina. $\mathrm{O}$ trabalho foi orientado pela vontade de entender as expressões locais das mudanças climáticas, sua interpretação por agricultores familiares e analisar a capacidade de adaptação das populações impactadas frente à uma nova realidade climática.

Como forma de se incluir a questão da comunicação nos moldes propostos por Habermas - "não através de cálculos egocêntricos de sucesso, mas através de atos de alcançar o entendimento" (Habermas, 1984, p. 285-286), a equipe de pesquisa se comprometeu com a restituição dos resultados junto à população pesquisada, também como parte de um compromisso ético com pesquisas em que grupos humanos são protagonistas.

A restituição de resultados é uma parte vital da produção do saber e um compromisso ético com os sujeitos envolvidos na investigação. Nesse sentido, os sujeitos da pesquisa científica devem ser enxergados como contribuintes-chaves para o entendimento dos resultados, por partirem do pressuposto de que, a partir desse diálogo, os saberes da equipe de pesquisa e dos próprios atores-alvo serão ampliados (Pessanha et al., 2013).

O educador Paulo Freire chamava essa comunicação de "diálogo amoroso" e a descrevia como um direito fundamental dos seres humanos, possível por meio da ação cultural que leva o indivíduo a uma conscientização de sujeito social com igualdade de oportunidades, direitos e deveres, mas, especialmente, como sujeito da inventividade da sua própria história. Freire estava preocupado com o outro, com os que são oprimidos; com aqueles que, no seu dizer, "apesar de Sujeitos criativos e transformadores - não têm voz própria, postura crítica, sofrem de dualidade existencial, de um senso de autodepreciação, e se caracterizam pela submissão e pelo silêncio" (Freire, 1977 apud Lima, 2011, p. 113). Realidade essa tristemente constatada em vários dos trabalhos de campo conduzidos durante a presente pesquisa. Vale lembrar que Freire equipara educação com comunicação, uma vez que não apenas utiliza ambos os termos indistintamente, mas também os iguala em sua epistemologia (Freire, 1971 apud Lima, 2011, p. 33).

Com o objetivo de fomentar o "protagonismo social territorial" dos agricultores familiares do semiárido - definimos "protagonismo social territorial" como o processo por meio do qual determinados atores sociais locais agem em coletividade como portadores da abordagem territorial e como principais impulsionadores da instalação, tanto da institucionalidade como do desenvolvimento territorial sustentável (Freitas et al., 2016; Miranda \& Tibúrcio, 2011) -, criou-se um espaço para a educação e a comunicação no âmbito do grupo de pesquisa. 
Buscou-se, especialmente, desenvolver um instrumento que proporcionasse diálogo de saberes com os atores locais sobre as mudanças climáticas e a restituição dos resultados na região estudada. Assim, foi elaborada a cartilha educativa Num Clima de Prosa: agricultura familiar e mudanças climáticas no sertão nordestino, no ano de 2014 , optando-se por esse modo de comunicação por conta do seu potencial em transmitir informação e compartilhar, nos dizeres de Freire (1971b), conhecimentos criativos e transformadores, de forma simples e adaptada às características locais e às necessidades do público-alvo.

Várias questões permearam o processo de desenvolvimento dessa ferramenta de comunicação, tais como: quais resultados merecem ser repassados? Quais informações levantadas seriam suscetíveis de serem entendidas pelos agricultores e, sobretudo, de serem úteis para ampliar seu conhecimento e apoiar suas atividades no campo? A partir de um processo bottom-up, que privilegiou os saberes tradicionais e comunitários, o instrumento de comunicação produzido levou em consideração as características regionais, os valores, as práticas e as expectativas dos agricultores familiares participantes da pesquisa. Além das percepções do clima, foram abordados, também a partir das experiências dos próprios agricultores, os mecanismos de adaptação que estão sendo utilizados na região.

A seguir, com o objetivo principal de levantar percepções sobre a relevância e os desafios de produzir uma comunicação científica sobre riscos climáticos que alcance os públicos mais vulneráveis às mudanças do clima, apresentaremos o processo participativo de elaboração e de restituição dos seus resultados da cartilha Num Clima de Prosa: agricultura familiar e mudanças climáticas no sertão nordestino. Para esta análise, serão apresentados alguns aspectos que consideramos relevantes ao compromisso de comunicar os riscos climáticos nas atividades agrícolas familiares. Sem a intenção de esgotar as análises sobre o tema, faremos uma contextualização da região e do público-alvo do estudo, uma breve análise sobre a percepção dos agricultores e trataremos dos desafios das barreiras perceptivas e das incertezas para comunicar as mudanças climáticas (MC).

\section{O contexto social e geográfico}

O Semiárido brasileiro abrange 1.133 municípios, localizados em nove estados: Alagoas, Bahia, Ceará, Minas Gerais, Paraíba, Pernambuco, Piauí, Rio Grande do Norte e Sergipe. Trata-se de um extenso território correspondente a pouco mais de um quinto do território brasileiro, onde caberiam a França e a Alemanha, por exemplo. Essa larga porção territorial é notadamente marcada pela diversidade cultural e natural. Contudo, a região é amplamente conhecida pelos longos períodos de seca que a assolam (Andrade, 2006).

Considerando-se as fontes de água permanentes disponíveis no Brasil, o semiárido detém apenas 3\% delas (CGEE, 2016). Assim, a dimensão territorial, o regime de chuvas da região e a distância das fontes de água permanentes localizadas no semiárido conformam o cenário de escassez de água disponível. Esse fenômeno tem impacto maior para os moradores das zonas rurais, que se encontram territorialmente dispersos, o que dificulta a implementação de um sistema público eficaz de abastecimento e distribuição de água.

O regime de chuvas da região é fortemente concentrado em quatro meses (fevereiro a maio), e a época de seca perdura aproximadamente pelos próximos oito meses do ano (CGEE, 2016). Somam-se ao regime de chuvas as características geológicas 
da região, onde o solo é predominantemente raso e encontra-se sobre rochas cristalinas, dificultando a perenidade dos rios. O território nordestino é mais de $80 \%$ constituído por rochas cristalinas (Rebouças, 1997). Há predominância de águas com teor elevado de sais que, via de regra, não são próprias para o consumo humano.

A concentração de terras e de água nessa região expressa fortemente a exclusão social dessa população. Uma realidade que atinge, em particular, cerca de 1,7 milhões de famílias agricultoras que vivem no Semiárido brasileiro. Assim, a adversidade das condições locais (naturais e sociais) levou, durante várias décadas, à visão de que era preciso "combater" a seca. Essa abordagem foi simbolizada, nos anos 1960 a 1980, pela construção de grandes obras de infraestrutura e pela manutenção de um sistema de açudes com base clientelista (Bursztyn \& Bursztyn, 2013).

Ao longo dos anos, a sociedade civil nordestina percebeu que, para garantir sua permanência no meio rural semiárido, além do emprego de tecnologias, era preciso abraçar uma proposta de desenvolvimento que valorizasse a região: o seu potencial econômico, o seu povo, as condições ambientais, desde que houvesse políticas públicas adequadas. Progressivamente, emergiu uma nova abordagem, sugerindo "conviver com o semiárido", ao invés de "combater a seca". Esse novo paradigma foi sendo construído ao longo dos anos pelas organizações locais, com base nos conhecimentos tradicionais.

Essa visão, que está em sintonia com a noção de sustentabilidade, buscará demonstrar que, sob certas condições, o semiárido pode se tornar uma região viável, em que políticas de convivência harmônica entre o modo de vida dos sertanejos e o meio ambiente podem proporcionar um modelo de desenvolvimento culturalmente adequado à região. Nesse contexto, o paradigma de convivência com o semiárido, demandado pela população local - que demonstrou e experimentou diversas técnicas de armazenamento de água, produção agrícola e criação de animais, adaptadas à realidade local -, trouxe à tona a necessidade de valorização do aprendizado a partir da realidade vivida, concedendo o protagonismo dessas ações aos próprios sertanejos.

\section{Métodos}

Por meio de uma pesquisa interdisciplinar, entre os anos de 2011 e 2013, 1.140 questionários foram aplicados pela equipe em quatro regiões do Semiárido brasileiro: Seridó Potiguar-RN, Gilbués-PI, Juazeiro-BA e Chapada do Araripe-CE (Figura 1).

Para a obtenção de informações mais gerais sobre as localidades estudadas, foram realizadas entrevistas semiestruturadas com atores institucionais-chaves em nível municipal e em algumas comunidades. Os roteiros de pesquisa usados nessa etapa foram elaborados pela equipe da sub-rede Mudanças Climáticas e Desenvolvimento Regional (MCDR/Rede CLIMA), ${ }^{1}$ tendo como base os questionários utilizados pela mesma equipe em outros campos nos Estados do Acre, Mato Grosso, Pará, Piauí, Bahia e Rio Grande do Norte. O primeiro roteiro visou a obtenção de dados gerais sobre o perfil produtivo da região, as dificuldades encontradas, as técnicas utilizadas, os programas governamentais em uso, os impactos da seca de 2012 e outras in-

\footnotetext{
${ }^{1}$ A sub-rede MCDR, coordenada pelo Centro de Desenvolvimento Sustentável da Universidade de Brasília (CDS/UnB), faz parte da Rede Brasileira de Pesquisas sobre Mudanças Climáticas Globais (Rede CLIMA).
} 
formações sobre logística para a segunda etapa dos trabalhos de campo.

Na segunda fase, uma equipe de pesquisadores foi treinada para a aplicação dos questionários socioeconômicos com agricultores familiares. Os questionários utilizados para entrevista incluíram questões semiestruturadas sobre características socioeconômicas do domicílio (ex.: educação); práticas produtivas (ex.: uso de insumos, tipos de culturas e animais); práticas adaptativas (ex.: mudanças nas culturas em resposta à variabilidade climática, técnicas de sucesso); e também percepção sobre mudanças ambientais e os principais desafios para a produção.

Sem tirar o foco da restituição de dados e do desenvolvimento da cartilha "Num Clima de Pro- sa”, a análise das informações se deu de diferentes formas. Primeiramente, todos formulários de entrevista foram conferidos e revisados, em busca de inconsistências, e tiveram seus dados inseridos em uma base de dados por meio do software SPHINX IQ. Para tal objetivo, os dados foram tratados sob o ponto de vista qualitativo, sem o estabelecimento de correlações ou significância entre as relações discutidas.

Para elucidar melhor a área de estudo e a abrangência da pesquisa, a seguir, seguem os campos realizados no Semiárido nordestino e a quantidade de questionários aplicados nas respectivas áreas (Figura 1).

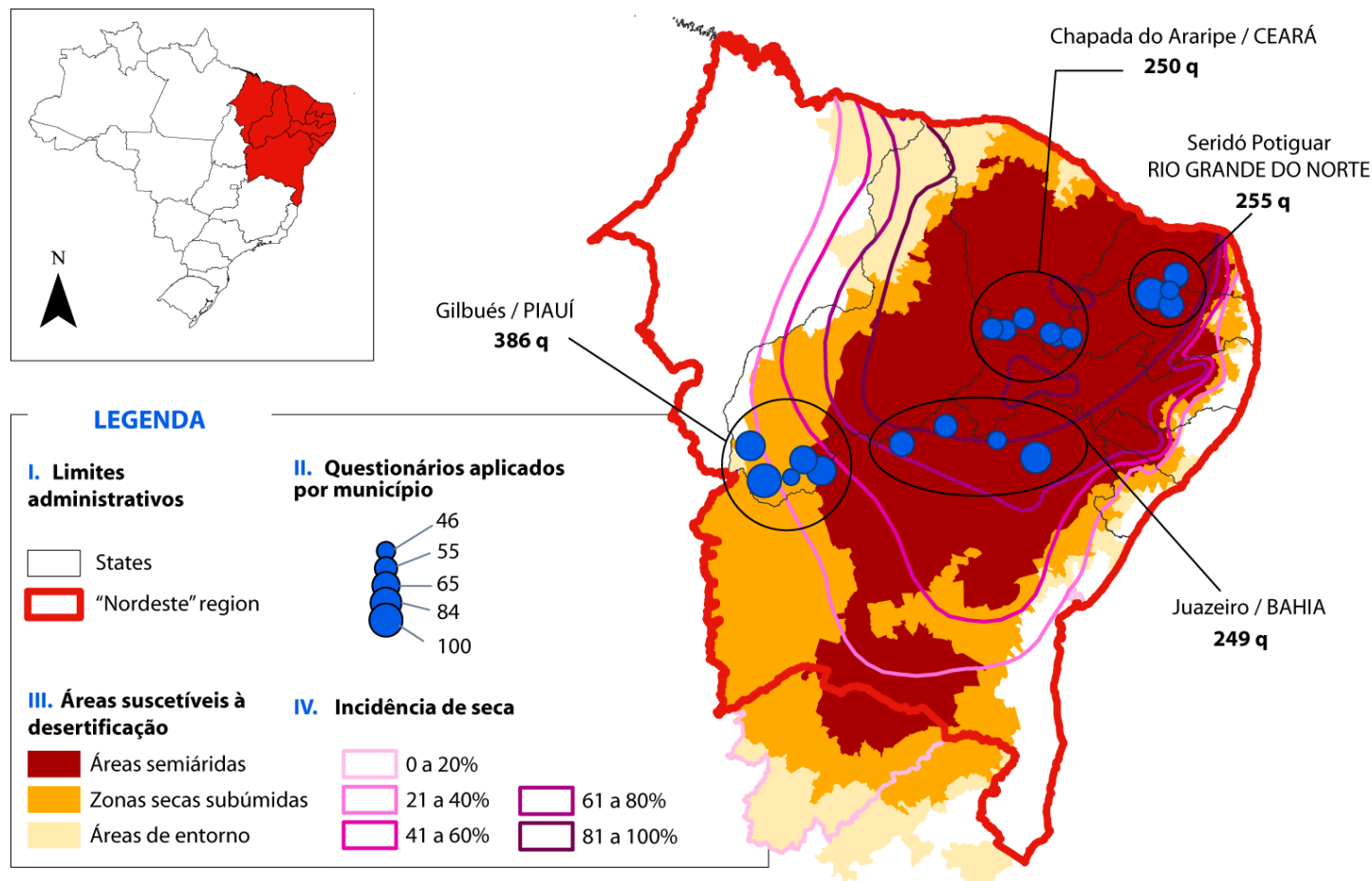

Fontes: Secretaria de Recursos Hídricos/MMA;IBGE; Sub-rede MCDR | C S. Nasuti, 2016

FIGURA 1 - Estudos de caso observados no Semiárido nordestino e a quantidade de questionários aplicados. FONTE: Nasuti et al. (2016). 


\section{Resultados}

\subsection{Preocupação com a restituição de resultados}

A criação de um instrumento de comunicação direcionado ao público-alvo da pesquisa não se traduz apenas como uma espécie de produto do estudo desenvolvido, mas, de modo mais significativo, apresenta-se como um compromisso ético dos pesquisadores em restituir os resultados da pesquisa aos seus interlocutores. Tem-se mostrado, também, como um momento de ampliação desses resultados e de desenvolvimento do poder de agir dos agricultores familiares diante das mudanças do clima.

No campo da ética em pesquisa, o tema da restituição dos resultados é uma questão emergente na agenda de debates internacionais. Cada vez mais, os comitês de ética em pesquisa exigem dos pesquisadores que explicitem como planejam devolver os resultados da pesquisa às comunidades ou às pessoas envolvidas na fase de coleta de dados (Diniz, 2008). O fato é que esse é um tema novo para as ciências humanas e ambientais, campos em que, geralmente, as pesquisas não alcançam públicos para além da comunidade acadêmica.

Embora estejamos utilizando o termo restituição, que significa devolver, dar novamente, consideramos as ressalvas de Rial (2014) muito pertinentes. A autora, ao tratar dos desafios na restituição da pesquisa antropológica, ressalta que dificilmente conseguimos de fato restituir os dados da pesquisa, pois a percepção e o interesse dos interlocutores são diversificados e, de modo geral, são diferentes da percepção e do interesse dos pesquisadores.

Entrega-se o resultado da pesquisa, mas não é possível garantir que o público receptor desses resultados considere o produto significativo no seu contexto individual ou social, como desejava o pesquisador. Como sugere a autora, talvez o termo mais apropriado continue sendo compartilhamento, algo já enraizado na antropologia (Rial, 2014).

Assim, com a proposta de compartilhar os resultados, propõe-se uma metodologia que envolve três etapas: $1^{\circ}$ ) criação: definição do tipo de material (no nosso caso, a cartilha educativa) e elaboração do produto; $2^{\circ}$ ) informação: distribuição das cartilhas e $3^{\circ}$ ) participação: realização de palestras, oficinas e grupos de discussão, em busca do diálogo entre pesquisadores, agricultores e outros públicos interessados (Curi et al., 2016a; 2016b). No caso da cartilha educativa aqui tratada, as três etapas (criação, participação e informação) já foram realizadas e serão descritas nos tópicos seguintes.

\subsection{Conteúdo e estrutura}

A cartilha tem como conteúdo a percepção dos agricultores familiares do Semiárido nordestino sobre as mudanças climáticas, as medidas de adaptação que estão sendo implementadas na região e uma explicação, com um enfoque mais educativo, sobre o clima na Região Nordeste e as variabilidades climáticas.

Além de ter sido formulada com o intuito de compartilhar os resultados coletados em campo com o público-alvo das pesquisas (os agricultores familiares), a cartilha tem se mostrado um instrumento educativo e de comunicação com outros atores sociais da região. Diante do seu conteúdo, ela foi divulgada na Universidade Federal do Cariri (região localizada no sul do Ceará), nas escolas de alguns municípios da região do Cariri e nas instituições colaboradoras da pesquisa, tais como a Embrapa, a Companhia Nacional de Abastecimento (Conab), o Sindicato dos Trabalhadores e a Empresa de Assistência Técnica e Extensão Rural (Emater). 
A escolha desse instrumento de divulgação se deu por se tratar de um tipo de material em que as informações podem ser transmitidas de maneira simples, objetiva e ilustrativa. A proposta foi de compartilhar conhecimentos, tanto científicos como tradicionais, por meio de história em quadrinhos, com diálogos curtos e adaptados ao linguajar local.

Vale ressaltar que a cartilha não se traduz apenas em um material educacional a respeito da visão científica em relação à mudança climática. Ela se apresenta como um instrumento de valorização sociocultural, pois busca demonstrar a importância da percepção das comunidades locais para a análise das mudanças do clima e para o estabelecimento de possíveis estratégias de adaptação.
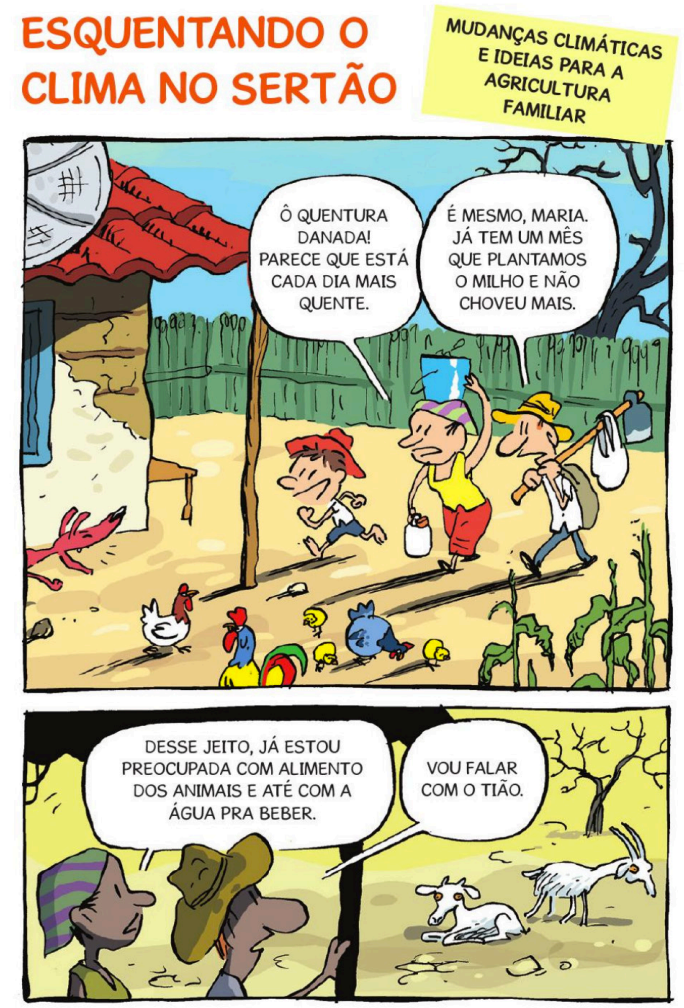

Em relação à estrutura, ela foi dividida em duas partes, ambas retratadas como história em quadrinhos. A primeira parte conta a história de um agricultor que percebe que a chuva está demorando a chegar e, por conta disso, vai conversar com um de seus vizinhos (Figura 2). Os amigos vão em busca de explicações e acabam conhecendo algumas estratégias de adaptação ao clima mais seco, que estão sendo utilizadas por outros agricultores locais (Figura 3). No último sítio visitado, aparece um jovem estudante, filho de agricultores da região. O menino menciona, pela primeira vez na história narrada, o termo "mudança climática", que é explicado ao final da cartilha, junto com outros temas relevantes abordados ao longo da história.

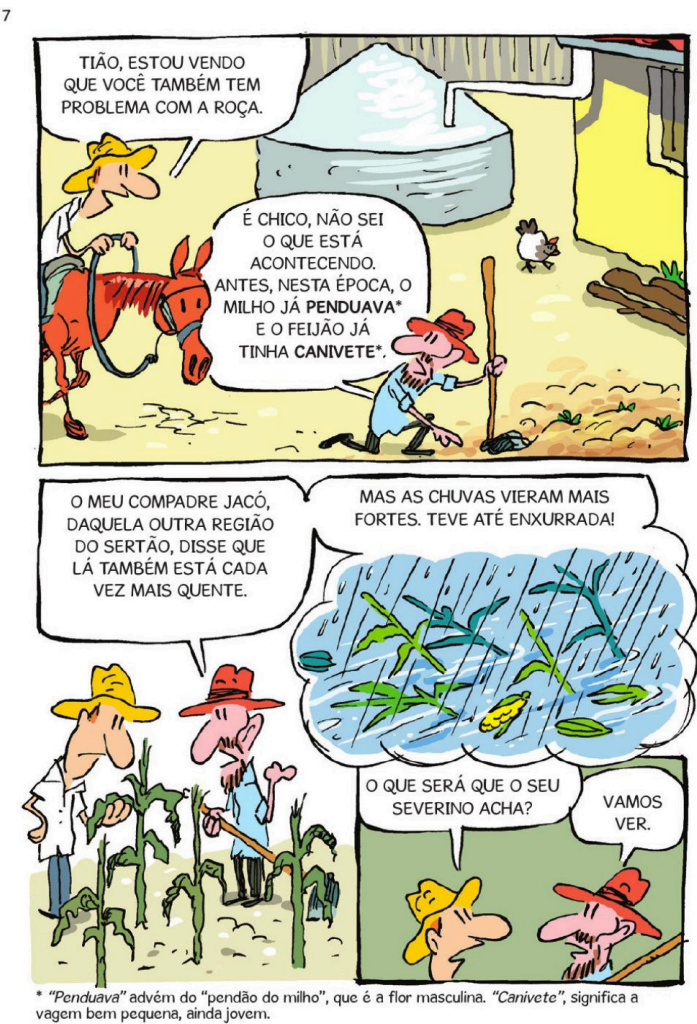

FIGURA 2 - Extrato da cartilha Num Clima de Prosa: agricultura familiar e mudanças climáticas no sertão nordestino (parte1). FONTE: Curi et al. (2014). 

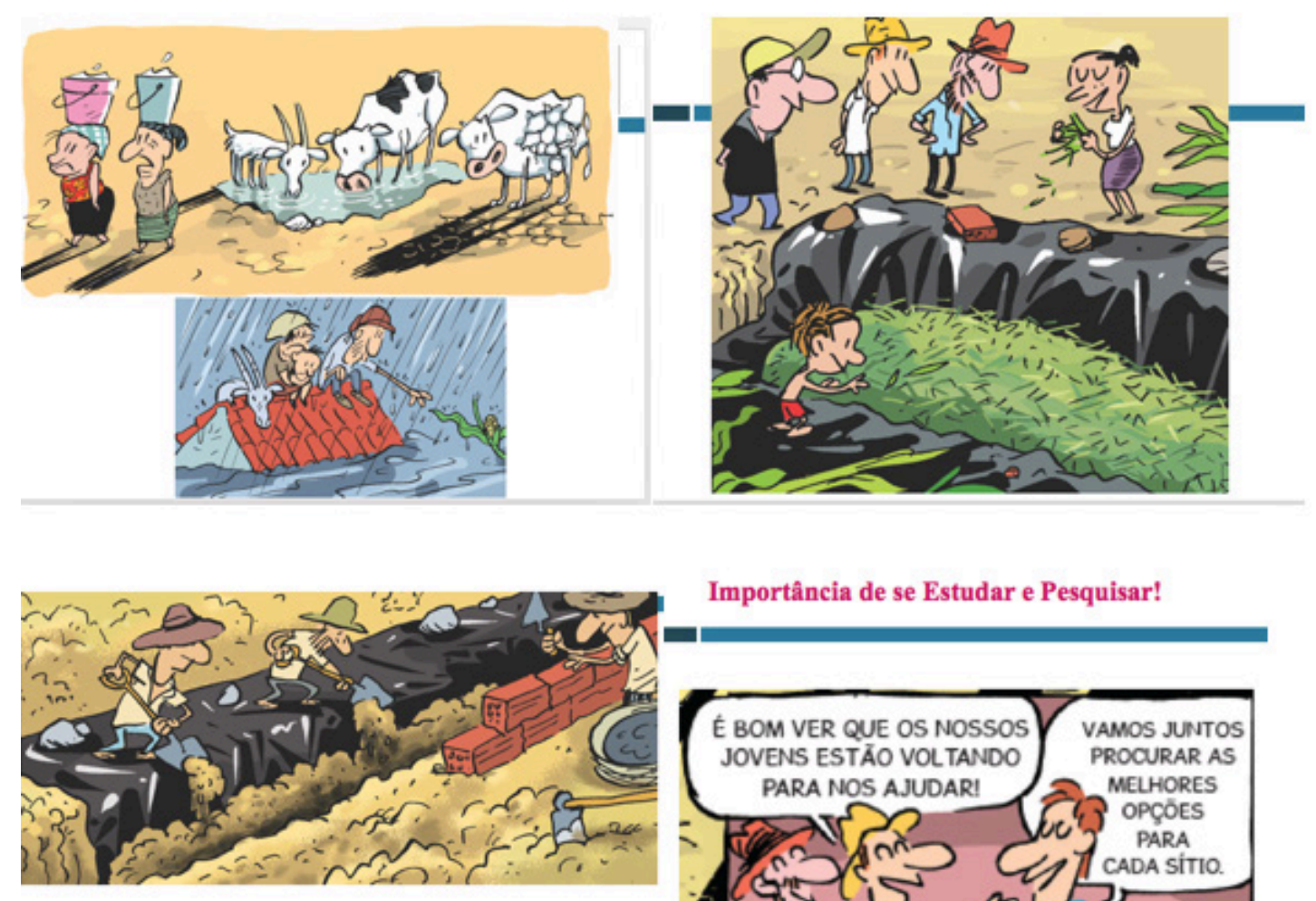

Importância de se Estudar e Pesquisar!

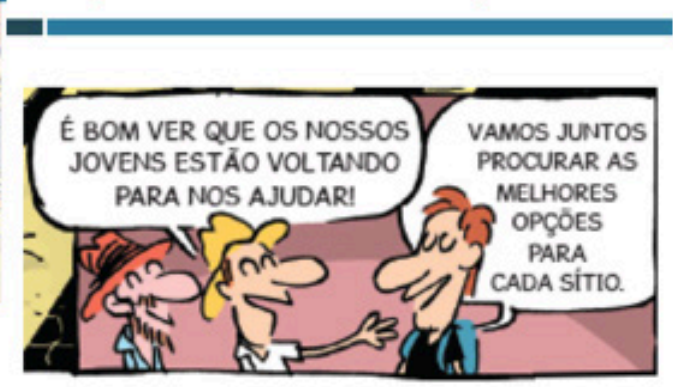

FIGURA 3 - Extrato da cartilha Num Clima de Prosa: agricultura familiar e mudanças climáticas no sertão nordestino medidas de adaptação.

FONTE: Curi et al. (2014).

Na segunda parte, o jovem estudante, com o objetivo de contribuir para um melhor planejamento do plantio das roças, formula uma explicação a respeito do regime de chuvas na Região Nordeste, relacionando assim os fenômenos observados localmente pelos agricultores com a problemática global da mudança climática (Figura 4).

Sempre buscando estabelecer uma relação amigável com um público pouco familiarizado com a informação impressa e que exige leitura, houve a preocupação de fazer dos desenhos mais do que uma "porta de entrada" para o texto escrito. A proposta principal era de que fossem um convite a ele. A ideia foi eliminar eventuais barreiras intimidadoras que a possibilidade de "ter que ler" pudesse criar. Para isso, era preciso ir além da mera ilustração do diálogo. Assim, ao passear pela cena do quadrinho, o leitor poderá perceber outras mensagens, ao redor daquela do primeiro plano, nos desenhos secundários (Curi et al., 2016b).

O desafio de ilustrar para a divulgação da ciência é colocar humor sem prejudicar a informação principal, que não pode conter erros. Em outras áreas, como a charge política, é possível haver mais 

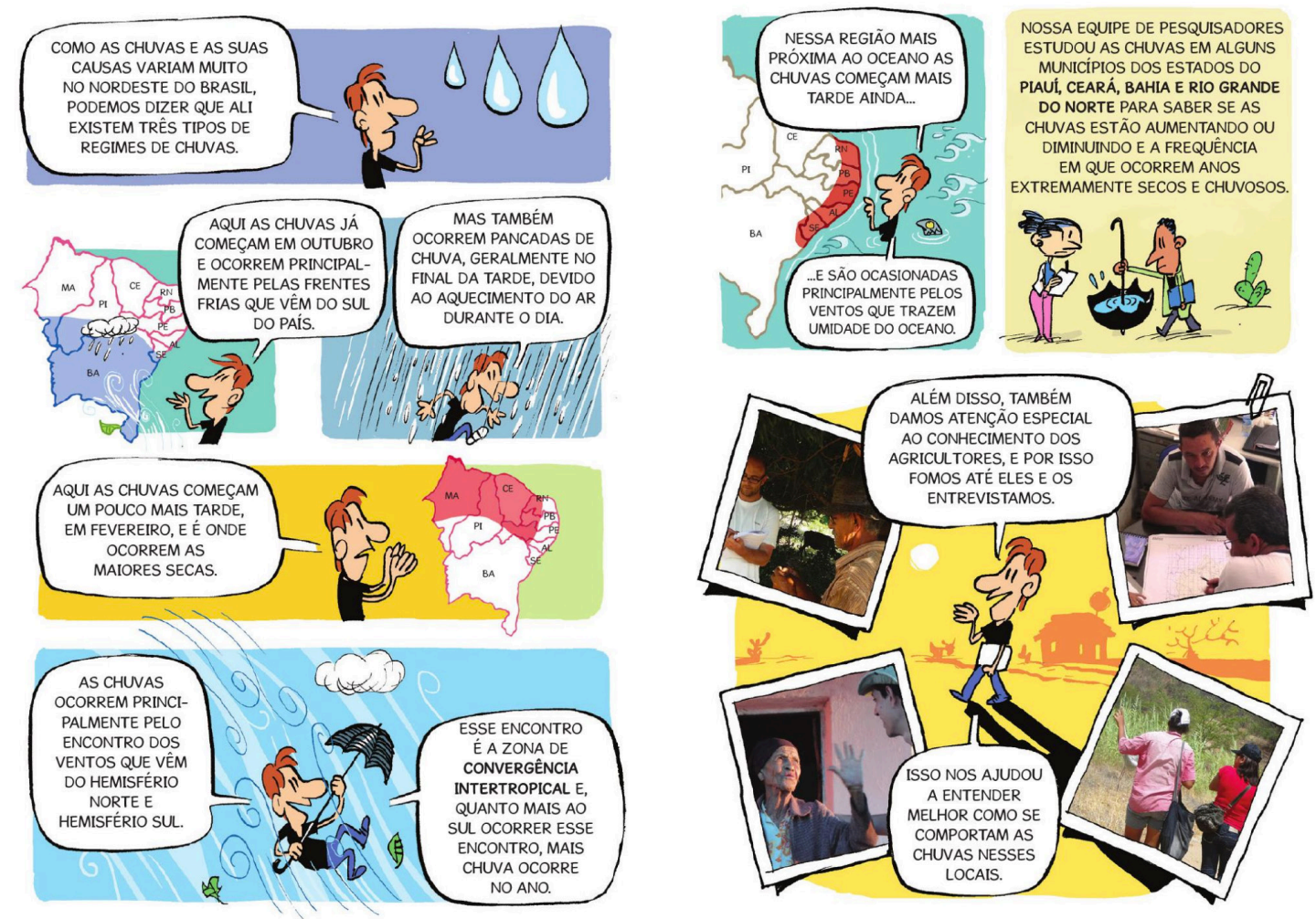

FIGURA 4 - Extrato da cartilha Num Clima de Prosa: agricultura familiar e mudanças climáticas no sertão nordestino (parte 2). FONTE: Curi et al. (2014).

de uma interpretação, dependendo da contextualização e do nível de informação do leitor sobre o assunto abordado. No caso da ciência, o propósito é informar e formar. Então, lança-se mão das ferramentas subjetivas, que são o humor e o desenho, para ilustrar algo muito objetivo.

\subsection{Adaptar os resultados de pesquisa ao instrumento de comunicação}

A cartilha foi essencialmente construída a partir da análise dos dados coletados por meio do questionário. Trata-se então de dados primários, que refletem o perfil sociodemográfico e econômico dos 1.140 agricultores entrevistados, as características dos sistemas produtivos, o grau de inserção das famílias em redes político-institucionais, suas percepções dos fatores ambientais e climáticos, os prejuízos sofridos em função do clima e as mudanças realizadas. Com esses dados, cobrimos o espectro da análise sobre vulnerabilidade climática: os vetores de exposição, a sensibilidade e a capacidade adaptativa (Adger, 2006). Mesmo possivelmente de forma simplificada, buscamos refletir esses três componentes na elaboração do conteúdo da cartilha.

Os dados de ordem sociodemográfica foram importantes para definir o "tipo ideal" do agricultor que seria retratado na cartilha: idade média entre 50 e 55 anos, com um nível de escolaridade baixo ( $55 \%$ da amostra não têm ensino fundamental com- 
pleto), o que configura condições difíceis de acesso e compreensão de certos tipos de informação. Em contrapartida, a população entrevistada tem forte identidade rural e uma profunda convivência com seu local de residência e produção. Por exemplo, no Seridó potiguar, $93 \%$ dos entrevistados nasceram e continuam morando no próprio estado.

Os questionários permitiram também caracterizar de forma fina o tipo da produção rural, que se caracteriza por uma escala muito pequena, associando geralmente o plantio de subsistência (milho, feijão, mandioca, arroz) em cultivos de sequeiro com a criação animal voltada, em função das regiões, para a ovino-caprinocultura ou a tradicional pecuária bovina.

Os dados sobre a percepção que os agricultores entrevistados têm das mudanças climáticas foram particularmente significativos para definir o roteiro da cartilha e aparecem em todas as partes. Logo, assim que percebemos o quanto era generalizada a percepção de que o tempo estava mudando e o quanto de incompreensões isso gerava entre os agricultores, resolvemos utilizá-los para "abrir" a cartilha. Com essa estratégia, almejamos suscitar uma "empatia" com o leitor e, assim, captar a atenção dele, ao associar uma situação potencialmente vivida com o conteúdo da cartilha.

Cerca de $90 \%$ da amostra, nas quatro áreas do Semiárido nordestino, confirma perceber alterações na fenologia local, nas temperaturas, mas essencialmente no regime de chuvas: na distribuição das precipitações no ano e na sua distribuição geográfica. A alteração do ritmo e intensidade das chuvas no inverno é completada por alterações nos períodos de veranico, reconhecidos como mais longos, ou seja, trazendo maiores riscos de perda da produção nas suas fases de desenvolvimento, como discutido por Nasuti et al. (2016). Todos esses parâmetros contribuem para aumentar a percepção que os agri- cultores têm de que sua produção é cada vez mais vulnerável e insegura, essencialmente em função de fatores hídricos, como retratado na cartilha, tanto na primeira quanto na segunda parte. Assim, em um primeiro momento, apoiamo-nos sobre as percepções levantadas para retratar as dúvidas geradas na mente dos agricultores entrevistados e, em um segundo momento, para explicá-las.

As informações sobre o grau de associativismo dos entrevistados foram importantes para inserir atores externos no roteiro da cartilha. Mesmo percebendo que a vida associativa varia bastante de um estado ao outro (por exemplo, no Piauí, cerca de $50 \%$ dos entrevistados não participam de nenhum grupo, enquanto no Rio Grande do Norte e na Bahia a taxa é de somente 18\%), essa informação permitiu identificar quais interlocutores são os mais presentes na realidade do interior. A inserção desses atores na cartilha permitiu fazer a ligação com as estratégias de adaptação mais significativas - como as cisternas calçadão, o plantio em curvas de nível ou o uso da silagem. De fato, é geralmente pela intermediação desses agentes que se alcança esse tipo de tecnologia. Assim, além de apresentar estratégias de adaptação testadas empiricamente, ao inserir as figuras do sindicato e do técnico de extensão rural, o objetivo foi orientar o leitor sobre os atores que deveriam ser acionados.

Enfim, buscamos valorizar as fontes de informação populares, amplamente divulgadas entre os entrevistados para identificar a chegada das chuvas, a partir da observação das plantas e dos animais. Nosso intuito foi ressaltar a relevância desses conhecimentos e seu potencial de convivência com as tecnologias e os conhecimentos científicos apresentados na cartilha. A título ilustrativo, descobrimos que a floração de uma determinada planta, como o mandacaru, e o movimento de certos animais, como o do pássaro joão-de-barro, são elementos que 
indicam a chegada da chuva ou o prolongamento da seca (Nasuti et al., 2013). Observando a familiaridade dos agricultores com esses temas, foi possível reconhecer que esses elementos seriam norteadores para conduzir o público do campo no caminho da sua leitura sobre mudança climática (Figura 5).

A segunda parte da cartilha foi motivada pelos resultados da última parte do questionário, em que o entrevistado era interrogado sobre seu conhecimento do conceito de mudança climática. Observamos que, apesar de a grande maioria dos respondentes já ter ouvido essa expressão, poucos sabiam explicá-la ou conseguiam associá-la às mudanças ambientais observadas no seu entorno.
Identificamos uma lacuna de informações, a qual a cartilha se propôs a preencher, ao comunicar, de forma mais didática, usando um formato inspirado nos "cordéis", ${ }^{2}$ tradicionais na região, sobre o fenômeno de mudança climática e suas manifestações territorializadas. Para explicar os efeitos locais, mobilizamos um conjunto diferente de dados. Trata-se de dados secundários, obtidos a partir dos registros diários de chuva da Agência Nacional de Águas (ANA) para um período de 100 anos, entre 1910 e 2010 , para as estações meteorológicas localizadas nas áreas de estudo (Fetter et al., 2016).

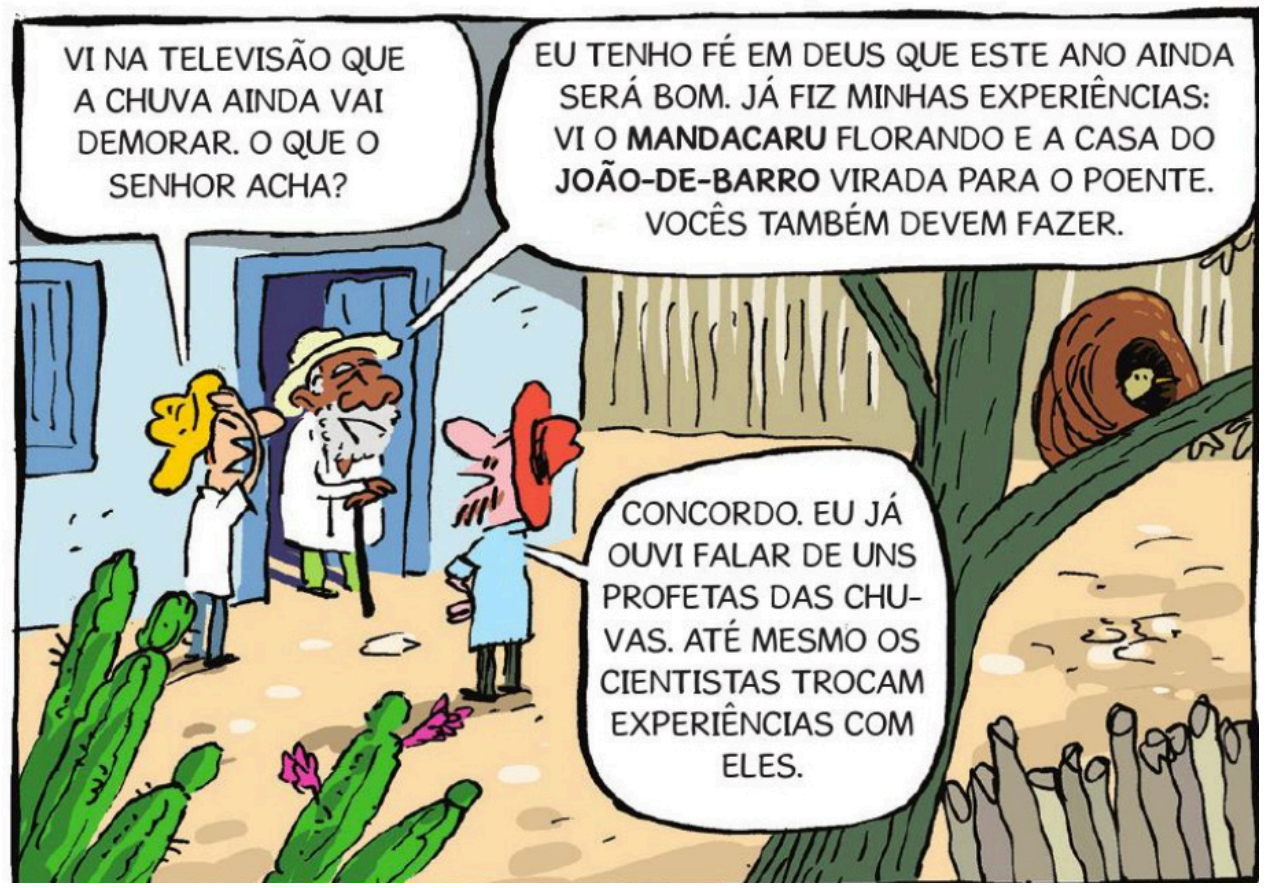

FIGURA 5 - Extrato da cartilha "Num Clima de Prosa: agricultura familiar e mudanças climáticas no sertão nordestino".

FONTE: Curi et al. (2014).

\begin{abstract}
2 Inspirada na literatura de cordel portuguesa, na qual os autores declamavam seus textos para o público acompanhados do som de uma viola, a popular literatura de cordel chegou ao Brasil pela mão dos colonos portugueses e ancorou no sertão nordestino. Por meio de um linguajar informal e de imagens coloridas, os cordéis abordam, de maneira didática e engajadora, ainda hoje, temas como a trajetória dos sertanejos e os desafios enfrentados pelo povo nordestino.
\end{abstract}




\subsection{Compartilhando os resultados}

Embora a cartilha tenha sido produzida no primeiro semestre do ano de 2014, o compartilhamento dos resultados só aconteceu em 2016. A falta inicial de recursos financeiros inviabilizou um retorno imediato aos campos, como previsto no projeto original, e restringiu a devolutiva a apenas uma região. Assim, em agosto de 2016, uma equipe formada por cinco pesquisadores da sub-rede MCDR se dirigiu ao Município de Juazeiro do Norte-CE (região do Cariri) para fazer o lançamento oficial da cartilha e compartilhar os resultados com os diversos atores sociais envolvidos na pesquisa.

O processo de restituição de resultados no Cariri, por meio da apresentação e distribuição da cartilha, aconteceu em duas fases. A primeira foi o lançamento da cartilha no campus da Universidade Federal do Cariri. Uma palestra sobre o tema Mudanças Climáticas e o Semiárido: o desafio da integração de políticas públicas, foi proferida por um dos coordenadores da sub-rede MCDR, seguida de uma apresentação das pesquisas e do conteúdo da cartilha por uma das pesquisadoras. Entre estudantes, professores, pesquisadores e convidados das instituições entrevistadas, o evento contou com a participação de mais de 200 pessoas e com uma ampla divulgação na mídia local. Todos os participantes e interessados presentes puderam obter a cartilha.

A segunda etapa da restituição dos resultados se deu com a distribuição de cartilhas para alguns dos atores institucionais de órgãos governamentais, associações, organizações não governamentais e sindicatos entrevistados na primeira fase dos trabalhos de campo. Nessa etapa, fez-se também a divulgação em algumas escolas da região.

Para divulgar a cartilha, foram visitadas 15 instituições locais, distribuídas entre os seguintes municípios: Altaneira, Barbalha, Crato, Juazeiro do Norte, Mauriti, Missão Velha e Salitre. Entre eles, Altaneira, Mauriti, Missão Velha e Salitre fazem parte da região estudada durante as pesquisas de campo.

A cartilha obteve uma ótima receptividade por parte dos representantes institucionais visitados. Todos se mostraram satisfeitos com os resultados e se dispuseram a auxiliar na divulgação do material junto aos agricultores familiares.

Concomitantemente à restituição aos atores institucionais, a cartilha foi divulgada aos estudantes e educadores de escolas de ensino médio. Foram selecionadas algumas escolas estaduais nas quatro cidades onde a pesquisa de campo na Chapada do Araripe foi realizada (Altaneira, Mauriti, Missão Velha e Salitre). Assim, equipes de dois e três pesquisadores percorreram as escolas e fizeram uma apresentação aos estudantes do $2^{\circ}$ e $3^{\circ}$ anos do ensino médio sobre mudanças climáticas e agricultura familiar, com o objetivo de que esses mesmos estudantes levassem as informações aos seus familiares, muitos deles agricultores familiares. De forma descontraída, participativa e com o uso de material visual, as equipes apresentaram o conteúdo da cartilha e disponibilizaram o material a todos os educadores e estudantes presentes.

\section{Discussão}

\subsection{Superando as barreiras perceptivas}

Historicamente, os contextos social e cultural, que desempenham papéis importantes na percepção dos indivíduos e na sua adesão a ações e políticas desenhadas para responder a choques e estresses climáticos, não vêm sendo devidamente considerados, tendo papel marginal nas análises (Adger et al., 
2009; Nielsen \& Reenberg, 2010). Isso tem gerado um descompasso entre as descobertas científicas e a aplicabilidade desse conhecimento.

Como exemplo do papel relevante do contexto social, vale mencionar a pesquisa de Jones \& Boyd (2011) nas zonas rurais do Nepal. Os autores identificam que a baixa autoestima feminina nessas regiões (uma barreira cultural que se torna cognitiva) faz com que as mulheres não se sintam capazes de empreender mudanças no ambiente. No mesmo sentido, Nielsen \& Reenberg (2010) relatam que, no norte de Burquina Faso, diferentes valores culturais levaram um grupo social a mudar seus modos de vida para se adaptar às mudanças do clima, enquanto que um outro grupo social da mesma região decidiu não agir.

No processo de adaptação, as percepções sobre os riscos climáticos e socioeconômicos integram a primeira das três fases: (i) compreensão do risco; (ii) planejamento da adaptação e (iii) gestão da adaptação (Moser \& Ekstrom, 2010). O processo de criação de um instrumento de comunicação sobre as mudanças climáticas, como a cartilha aqui apresentada, contribui para a compreensão do risco. Destaque-se que, nesse esforço de compreensão do risco, as percepções ajudam na identificação e comunicação do problema e no levantamento de opções úteis de adaptação (Maddison, 2006; Gbetibouo, 2009; Moser \& Ekstrom, 2010; Litre \& Bursztyn, 2015).

Uma melhor compreensão dos valores e processos envolvidos, tanto nas relações entre os grupos como entre estes e o meio ambiente, configura uma etapa indispensável para a superação de barreiras reais à adaptação. Isso é especialmente verdadeiro no caso dos usuários que trabalham na agricultura, que percebem, de maneira seletiva, os riscos atrelados às mudanças do clima e aos choques socioeconômicos. Em outras palavras, a percepção é temporal, porque se trata de um fenômeno de curto prazo, o que dificulta o registro das mudanças que acontecem no longo prazo, como as mudanças do clima.

Ao mesmo tempo, a forma como os indivíduos levam a cabo o processo de percepção evolui na medida em que se enriquecem as suas experiências ou variam as suas necessidades e motivações (Litre, 2010; Rao et al., 2011). Assim, torna-se difícil perceber fatores novos, frente aos quais agricultores familiares não têm experiência prévia, como novos parâmetros na mudança e variabilidade do clima (Slovic, 2000). Também não é fácil para o usuário perceber e reagir a mudanças sutis que demoram anos para evidenciar seu impacto. Existe, finalmente, uma "defesa perceptiva": as pessoas negam o que não lhes convém, evitam inconscientemente ter estímulos desagradáveis, podendo, inclusive, distorcer uma informação que seja incongruente com as suas necessidades, valores, crenças religiosas, etc. (Slovic, 2000).

A partir dessa realidade, a estratégia de comunicação participativa e de construção bottom-up, como a adotada na produção da cartilha educativa para os agricultores familiares no semiárido, colocou as percepções dos usuários dos recursos naturais e dos atores-chave em primeiro plano. Mas, como explicamos, nem sempre a existência de conhecimento sobre essas percepções implica que ele vai se transformar em ação e em mudanças concretas de atitude face aos riscos climáticos. De fato, vincular a informação científica e o conhecimento com ações concretas tem se revelado mais difícil do que o esperado, especialmente na área da sustentabilidade (Matson et al., 2016).

As barreiras sociais e cognitivas à adaptação não são absolutas e podem ser superadas por meio de esforços concentrados, gestão e comunicação criativas, mudanças de pensamento e das estruturas 
institucionais, estabelecimento de prioridades e apresentação de novas formas de uso dos recursos naturais.

Essas mudanças devem partir do pressuposto de que os usuários finais do conhecimento somente vão agir a partir dessas informações se elas forem percebidas como realmente relevantes, críveis e legítimas. Como pode a comunicação científica contribuir para atingir esses três objetivos? Matson et al. (2016) salientam a triste realidade de que muitas descobertas científicas nunca saem das páginas de periódicos científicos ou livros acadêmicos, deixando soluções em potencial afastadas de inúmeras necessidades que poderiam ser resolvidas (Matson et al., 2016, p. 105).

Para os autores, o único conhecimento realmente influente é o conhecimento confiável. Para ser confiável, esse conhecimento deve superar, desde o início, a habitual desconfiança existente entre os "produtores de informação científica" e os usuários dessa informação. Em outras palavras, a barreira da desconfiança mútua deve ser superada por meio de conhecimentos produzidos, desde o início, de maneira colaborativa.

Frequentemente, os produtores de conhecimento ou especialistas assumem que entendem $a$ priori quais são os problemas e as soluções que melhorarão o bem-estar dos "usuários finais" (tomadores de decisão, comunidades-alvo etc.). Porém, nem sempre essa agenda de prioridades estabelecida por cientistas e outros especialistas, mesmo se carregada de boas intenções, coincide com a agenda do chamado "público-alvo", que não outorga legitimidade, credibilidade e relevância ao conhecimento oferecido.

Como superar essa barreira da desconfiança e da incompreensão mútuas? Foi esse um dos principais desafios enfrentados pela equipe da sub-rede MCDR no momento de transformar dados científicos sobre o clima no semiárido em conhecimento realmente útil (com potencial de se transformar em ações efetivas de adaptação). Levando isso em consideração, o processo completo de elaboração da cartilha foi realizado compartilhando conhecimentos.

Nesse movimento colaborativo, a equipe de pesquisadores criou, desde a fase de planejamento da pesquisa e da coleta de dados, uma estratégia que incluía o diálogo horizontal e, nas palavras de Paulo Freire, "amoroso", com atores, em geral não acadêmicos, porém altamente "criativos e transformadores" (Freire, 1977), como extensionistas rurais, os próprios agricultores familiares e tomadores de decisão nacionais e locais. Antes das pesquisas de campo "oficiais", foram realizadas visitas de campo-piloto e oficinas de trabalho nas universidades (Universidade de Brasília - UnB, e instituições locais - UFC/Cariri, UFRN, UAPI, UESPI, UEFS).

Assim, os produtores de conhecimento e os usuários desse conhecimento trocaram papeis e trabalharam juntos para: i) identificar os principais riscos climáticos e entraves adaptativos da região; ii) criar possíveis estratégias de adaptação e de redução da vulnerabilidade aos riscos climáticos percebidos; e iii) avaliar a eficácia (ou não) dessas possíveis estratégias de adaptação a partir de critérios definidos de maneira participativa (funciona, ou não? Qual é o custo financeiro, familiar etc. de fazer ou não fazer isso?).

Esse tipo de atividade colaborativa outorga maior confiabilidade aos resultados da pesquisa, empodera os atores envolvidos, incrementa a ownership dos resultados e aumenta as chances de que as novas informações se transformem em ações adaptativas e mudanças de atitudes (Matson et al., 2016, p. 118). No caso concreto das cartilhas, foi interessante perceber, durante a fase de disseminação, até que ponto o público (por exemplo, alunos de escolas que são filhos de agricultores) 
se sentiu espelhado pelas realidades descritas na cartilha, como a migração forçada para as cidades por fatores climáticos e as incertezas a respeito do futuro das famílias.

\subsection{Superando a rejeição à incerteza}

Não gostamos de incertezas. Praticamente todos preferimos confiar que, quando o semáforo fica verde, podemos avançar sem problemas. Buscando a adaptação no contexto das mudanças climáticas, é possível confiar e contornar a incerteza por meio de uma efetiva comunicação científica? No estado atual de conhecimento, a produção de cenários climáticos não permite responder positivamente a essa pergunta. Existe um importante componente de incerteza ligado à variabilidade inerente ao clima e aos recursos naturais.

O clima apresenta variabilidade sazonal e interanual, no espaço e no tempo, variando de horas até milênios. De acordo com Bradshaw \& Borchers (2000), a ideia de que uma maior certeza pode ser obtida baseia-se na suposição errônea de que a incerteza é finita. Se a incerteza é parte inerente da ciência, indicando para os cientistas um caminho de novos desafios e superações, para as políticas públicas, ela tende a gerar insegurança e indecisão (Litre, 2014).

O que se pode afirmar é que, embora os cientistas tenham um panorama significativo de como funciona o sistema climático, eles não têm 100\% de confiança nas projeções sobre as mudanças do clima e suas consequências. Esse fato não deixa os usuários do conhecimento muito satisfeitos, especialmente os tomadores de decisão, que enfrentam eleições a cada quatro anos, e os agricultores, que suportam grande parte dos custos financeiros das inovações adaptativas propostas pelos especialistas.
Porém, assumir que persiste uma porção de incerteza não significa não saber o suficiente para agir e comunicar. O que pode ser feito são previsões com base nos melhores dados disponíveis, quantificar as incertezas associadas a essas previsões, identificar as frentes de ação nas quais é possível reduzi-las e agir com base no princípio da precaução, considerando-se, ao mesmo tempo, a existência do custo de não agir.

Em outras palavras, gerenciar e comunicar de maneira clara os riscos e também as oportunidades originadas pelas mudanças climáticas, considerando-se as incertezas e as fragilidades estruturais como pano de fundo, é o desafio atual de qualquer estratégia de comunicação de adaptação, incluindo a criação de cartilhas educativas para os agricultores familiares. Em outras palavras, oferecer informação crível e confiável nesse contexto de incerteza não é tarefa fácil. Como podem os agricultores familiares do sertão chegarem à conclusão de que a informação fornecida nas cartilhas é confiável e legítima, se as mudanças climáticas estão mergulhadas na incerteza científica?

Para um cientista, o resultado da pesquisa pode ser descrito como confiável pelo fato de ter representatividade estatística e uma metodologia clara e replicável. Porém, esses critérios científicos podem não ser relevantes para um agricultor familiar que pretenda saber, por meio de conversas com seus vizinhos, se uma estratégia produtiva, como a silagem, realmente funcionou e com que custo financeiro. Reparar a falta de credibilidade e reduzir (dentro do possível) as incertezas requer observar de que maneira o conhecimento está sendo produzido a partir da perspectiva (e percepções) dos usuários, entender que tipo de evidência convenceria esses usuários da confiabilidade e credibilidade dos resultados da pesquisa e trabalhar com todos os participantes para estabelecer critérios de avaliação conjunta (Matson et al., 2016, p. 114-115). 


\section{Considerações finais}

O presente artigo buscou exemplificar como estratégias de restituição de resultados de pesquisa em mudanças climáticas podem auxiliar no processo de comunicação dos impactos, oportunidades e modo de adaptação de populações vulneráveis, como os agricultores familiares do semiárido.

Por meio da criação de histórias em quadrinhos, utilizando dados qualitativos de uma vasta pesquisa de campo, foi possível, de forma simples e ilustrativa e com diálogos curtos e adaptados ao linguajar local, prover informações sobre as mudanças do clima à população local. Reconhecendo a especial relação dos agricultores familiares e do seu modo de vida com a terra e com os fenômenos da natureza, a narrativa espelhou-se na realidade de agricultores que estão tendo que se adaptar a uma variação climática, que transcende as secas características da região.

As particularidades da linguagem verbal e não verbal usadas nas cartilhas quadrinizadas para apresentar informações científicas facilitaram a disseminação de explicações científicas a respeito das variações climáticas locais, que estão sendo observadas pelos agricultores familiares e também confirmadas pela equipe de pesquisa.

A respeito da cartilha educativa como instrumento concreto de restituição de resultados às comunidades-alvo, concluímos que o uso de história em quadrinhos constitui uma possível estratégia de sedução pelo lúdico e, eventualmente, de facilitação da leitura, em uma população com baixo nível escolar.

Ao mesmo tempo, a cartilha procura apresentar os conceitos científicos expostos de forma didática, mesclando traços da linguagem científica e do registro usado nas histórias em quadrinhos, nas quais há uma tendência aos diálogos informais, já que boa parte das interações na agricultura familiar nordestina se dá com base em conversações face a face. Por outro lado, reconhecem-se a limitação e os desafios do instrumento, tais como a dificuldade intrínseca ao próprio produto (um material impresso de leitura), que restringe o acesso do conteúdo por parte do público analfabeto.

Além de cumprir com um compromisso ético de pesquisa no momento de divulgação dos resultados de forma didática e acessível a um público não acadêmico, a descrição da experiência de comunicação sobre o clima possibilita que outros grupos de pesquisa se espelhem e façam as suas próprias análises sobre os pontos positivos e limitações aqui apresentados. A pressão pelo acesso da sociedade aos conhecimentos construídos no universo acadêmico tende a tornar a área de comunicação e divulgação científica parte crucial em qualquer projeto de pesquisa, o que dará mais visibilidade e importância aos resultados acadêmicos produzidos.

Finalmente, e num nível mais amplo, a receptividade positiva da cartilha Num Clima de Prosa: agricultura familiar e mudanças climáticas no sertão nordestino como instrumento de comunicação de conhecimentos sobre as mudanças climáticas confirmou o pressuposto de que as comunidades locais tendem a confiar em novas informações ao perceberem atributos de relevância, credibilidade e legitimidade.

Os resultados gerais da experiência demonstraram que as barreiras que, em geral, impedem transformar informações científicas em conhecimento influente (como a desconfiança mútua), podem ser superadas por meio de ações colaborativas entre a academia, os tomadores de decisão e os usuários finais. Nesse sentido, a elaboração da cartilha encorajou o trabalho horizontal para identificar riscos climáticos, criar opções de adaptação para responder a esses riscos e avaliar o desempenho dessas opções a partir de critérios definidos em conjunto. 


\section{Referências}

Adger, W. N. Vulnerability. Global Environmental Change, 16(3), 268-281, 2006.

Adger, W. N.; Dessai, S.; Goulden, M.; Hume, M. Are there social limits to adaptation to climate change? Climatic Change, 93 (3-4), 335-354, 2009.

Andrade, M. C. A terra e o homem no Nordeste. 7. ed. São Paulo: Cortez, 2006.

Beck, U. La sociedad del riesgo: hacia una nueva modernidad. Barcelona: Paidós, 1998.

Beck, U. O que é globalização? Equívocos do globalismo: respostas à globalização. São Paulo: Paz e Terra, 1999.

Beddington, J.; Asaduzzaman, M.; Clark, M.; Fernández, A.; Guillou, M.; Jahn, M.; Erda, L.; Mamo, T.; Van Bo, N.; Nobre, C. A; Scholes, R.; Sharma, R.; Wakhungu, J. Achieving food security in the face of climate change: Final report from the Commission on Sustainable Agriculture and Climate Change. CGIAR Research Program on Climate Change, Agriculture and Food Security (CCAFS). Copenhagen, Denmark. 2012.

Bradshaw, G. A.; Borchers, J. G. Uncertainty as Information: Narrowing the Science-policy Gap. Conservation Ecology, 4(1), 7, 2000.

Bursztyn, M. A; Bursztyn, M. O. Poder dos donos. Rio de Janeiro: Garamond, 2013.

CGEE - Centro de Gestão e Estudo Estratégicos. A questão da água no Nordeste. 2016. Disponível em: <http://www. cgee.org.br/eventos/Agua_Nordeste/contextualizacao. $\mathrm{htm}>$. Acesso em: out. 2016.

Curi, M.; Litre, G.; Nasuti, S.; Dalboni Rocha, J. (Eds.). Num clima de prosa: agricultura familiar e mudanças climáticas no sertão nordestino (Climate Change and Family Farming in the Brazilian Northeastern Sertão - Cartilha/ Booklet). Brasília: Universidade de Brasília, Centro de Desenvolvimento Sustentável, 2014.

Curi, M.; Litre, G.; Ibiapina, I.; Andrade, A. J. P. Mudanças climáticas e percepção ambiental: contribuições da Antropologia do Clima. In: Bursztyn, M.; Rodrigues-Filho, S. (Orgs.). O clima em transe. Rio de Janeiro: Garamond, 2016a. p. 35-52.
Curi, M.; Litre, G.; Veiga, A. P. S. O compromisso com a restituição de resultados da pesquisa. In: Bursztyn, M.; Rodrigues-Filho, S. (Orgs.). O clima em transe. Rio de Janeiro: Garamond, 2016b. p. 77-92.

Diniz, D. Ética na pesquisa em ciências humanas: novos desafios. Revista Ciência e Saúde Coletiva, 13, 2, 2008.

Fetter, R.; Henke, C.; Debortoli, N.; Saito, C. H. A contribuição da análise espaço temporal de dados climáticos. In: Bursztyn, M.; Rodrigues-Filho, S. (Orgs.). O clima em transe. Rio de Janeiro: Garamond, 2016. p 219- 245.

Freire, P. Extensão ou comunicação. Rio de Janeiro: Paz e Terra, 1971a.

Freire, P. Educação como prática de liberdade. Rio de Janeiro: Paz e Terra, 1971b.

Freire, P. Pedagogia do oprimido. Rio de Janeiro: Paz e Terra, 1977.

Freitas de Abreu, M. K.; Salgueiro do Nascimento, V.; Alencar Brasil, A.; Pinho Andrade, D. Protagonismo social e suas contribuições para o desenvolvimento rural sustentável: um estudo de caso no município de Caririaçu - Ceará (Brasil). Sustentabilidade em Debate, 7 (Edição Especial), 152-168, 2016.

Gbetibouo, G. A. Understanding Farmers Perceptions and Adaptations to Climate Change and Variability: the case of Limpopo Basin, South Africa. International Food Policy Research Institute, 2009.

Giddens, A. O mundo na era da globalização. 4. ed. Lisboa: Presença, 2000.

Giddens, A.; Beck, U; Lash, S. Modernização reflexiva: política, tradição e estética na ordem social moderna. São Paulo: Unesp Editora, 1997.

Habermas, J. The theory of communicative action. Vol 1. Reason and the rationalizalion of society. Boston: Beacon Press, 1984.

Habermas, J. The theory of communicative action. Vol 2. Lifeworld and system: A critique of functionalist reason. Boston: Beacon Press, 1987. 
IBGE - Instituto Brasileiro de Geografia e Estatística. XII Recenseamento Geral do Brasil. 2010. Disponível em: $<\mathrm{http}$ ://censo2010.ibge.gov.br/>. Acesso em: set. 2016.

INSA - Instituto Nacional do Semiárido. O Semiárido brasileiro: riquezas, diversidade e saberes. 2014. Disponível em: <http://www.insa.gov.br/>. Acesso em: maio 2015.

Jones, L.; Boyd, E. Exploring social barriers to adaptation: Insights from Western Nepal. Global Environmental Change, 21(4), 1262-1274, 2011.

Lima, V. A. Comunicação e cultura: as ideias de Paulo Freire. Prefácio de Ana Maria Freire. 2. ed. rev. Brasília: Editora da UnB, Fundação Perseu Abramo, 2011.

Litre, G. Os gaúchos e a globalização: vulnerabilidade e adatação da pecuária familiar no pampa do Uruguai, Argentina e Brasil. Paris, Tese (Doutorado) - Centro de Desenvolvimento Sustentável, Universidade de Brasília - IHEAL/ CREDAL, Paris III, Sorbonne-Nouvelle, maio de 2010.

Litre, G. Scientific Uncertainty and Policy Making: How Can Communications Contribute to a Better Marriage in the Global Change Arena? In: Braimoh, A. K.; Huang, H. Q. (Orgs.). Vulnerability of Land Systems in Asia. London: Wiley-Blackwell, 2014. p. 311-319.

Litre, G.; Bursztyn, M. Family Farmers' Perceptions and Adaptation Strategies to Climatic and Socioeconomic Risks in the Pampa Biome-South America. Ambiente \& Sociedade, 18, 55-80, 2015.

Maddison, D. The perception of and adaptation to climate change in Africa. CEEPA Discussion Paper No. 10. Centre for Environmental Economics and Policy in Africa, University of Pretoria, South África, 2006.

Matson, P.; Clark, W. C.; Andersson, K. Pursuing Sustainability. A Guide to Science and Practice. Princeton and Oxford: Princeton University Press, 2016.

Miranda, C.; Tibúrcio, B. Políticas públicas, atores sociais e desenvolvimento territorial no Brasil. In: Sérgio Pereira Leite et al. (autores); Miranda, C.; Tibúrcio, B. (Org.). Série Desenvolvimento Rural Sustentável, v. 14, Brasília: IICA, 2011.

Moser, S. C.; Ekstrom J. A. A framework to diagnose barriers to climate change adaptation. Proceedings of the National Academy of Sciences of the United States of America, 107(51), 22026-22031, 2010. doi: 10.1073/ pnas. 1007887107

Nasuti, S.; Curi, M. V.; Silva, N. M.; Andrade, A. J. P.; Ibiapina, I.; Souza, C. R.; Saito, C. H. Conhecimento tradicional e previsões meteorológicas: agricultores familiares e as "experiências de inverno" no semiárido Potiguar. Revista Econômica do Nordeste, 44(5), 11-32, 2013. Disponível em: $<$ https://ren.emnuvens.com.br/ren/article/viewFile/37/19>.

Nasuti, S.; Litre, G.; Gucciardi-Garcez, C.; Da Silva, C.; Nogueira, P. Percepções de pequenos agricultores sobre o clima. Comparação entre os biomas Amazônia, Cerrado, Caatinga e Pantanal. In: Bursztyn, M.; Rodrigues-Filho, S. (Orgs.). O clima em transe. Rio de Janeiro: Garamond, 2016. p. 197- 218.

Nielsen, G. O.; Reenberg, A. Cultural Barriers to Climate Change Adaptation: A Case Study from Northern Burkina Faso. Global Environmental Change, 20, 142-152, 2010.

Obermaier, M.; Maroun, M. R.; Kligerman, D. C.; La Rovere, E. L.; Cesano, D.; Corral, R.; Wachsmann, U.; Schaller, M.; Hain, B. Adaptation to Climate Change in Brazil: The Pintadas Pilot Project and Multiplication of Best Practice Examples through Disseminaton and Communication Networks. RIO 9 - World Climate \& Energy Event, p. 1-6, 2009.

Pessanha, J.; Silva, C. O.; Rotenberg, L. Uma experiência de restituição de resultados em saúde do trabalhador. Revista ECOS - Estudos Contemporâneos da Subjetividade, 3(1), 32-44, 2013. Disponível em: <http://www.uff.br/periodicoshumanas/index.php/ecos/article/view/1124>. Acesso em: jan. 2015.

Pinto, J. M. R. A teoria da ação comunicativa de Jürgen Habermas: conceitos básicos e possibilidades de aplicação à administração escolar. Paidéia, 8, 77-96, 1995. doi: 10.1590/S0103-863X1995000100007

Rao, K. P. C.; Ndegws, W. G.; Kizito, K.; Oyoo, A. Climate Variability and Change: Farmer Perceptions and Understanding of Intra-Seasonal Variability in Rainfall and Associated Risk in Semi-Arid Kenya. Expl. Agric., 47(2), 267-291, 2011.

Rebouças, A. C. Água na Região Nordeste: desperdício e escassez. Estudos Avançados, 11(29), 127-154, 1997. doi: 10.1590/S0103-40141997000100007

Rial, C. S. M. Roubar a alma: ou as dificuldades da restituição. Tessituras, 2(2), 201-212, 2014. Disponível em: 
$<$ https://periodicos.ufpel.edu.br/ojs2/index.php/tessituras/ article/view/4879/3768>.

Silva, N. M. Experiências de inverno no Seridó Potiguar. Natal, Dissertação (Mestrado em Meio Ambiente, Cultura e Desenvolvimento) - UFRN, 2013.

Slovic, P. The perception of risk. London, UK: Earthscan, 2000.
Vermeulen, S. J.; Aggarwal, P. K.; Ainslie, A.; Angelone, C.; Campbell, B.N.; Challinor, A. J.; Hansen, J.; Ingram, J. S. I.; Jarvis, A.; Kristjanson, P.; Lau, C.; Nelson, G. C.; Thonton, P. K.; Wollemberg, E. Agriculture, Food Security and Climate Change: Outlook for Knowledge, Tools and Action. CCAFS Report 3. CGIAR-ESSP Program on Climate Change, Agriculture and Food Security. p. 1-16, 2010. 